\title{
PREDICTORS OF GOOD GLYCEMIC CONTROL AMONG TYPE II DIABETES PATIENTS IN PALESTINE
}

\section{RAMI SALEM MOSLEH ${ }^{1 *}$, NOORIZAN ABD. AZIZ ${ }^{1}$, SALMIAH MOHD ALI ${ }^{1}$, MOHAMED MANSOR MANAN ${ }^{1}$, SA'ED ZYOUD $^{1}$, ISMAIL MOHD SHAH ${ }^{1}$, YAZUN BASHIR JARRAR ${ }^{2}$}

\begin{abstract}
${ }^{1}$ Department of Pharmacy Practice, Faculty of Pharmacy, Universiti Teknologi MARA (UiTM), UiTM Puncak Alam, 43600 Bandar Puncak Alam, Selangor Darul Ehsan, Malaysia. ${ }^{2}$ College of Pharmacy, Al-Zaytoonah University, Amman, Jordan. Email: rami_musleh123@hotmail.com
\end{abstract}

Received: 28 April 2017, Revised and Accepted: 06 June 2017

ABSTRACT

Objectives: The aim of this study is to assess glycemic control and its relationship with patient characteristics, health-care system factors, and self-care management in type II diabetes patients.

Methods: A retrospective cross-sectional study was conducted among 330 type II diabetes patients who met the inclusion criteria and whose medical records covered a period of 1 year. Data concerning patient characteristics, health-care system factors, self-care management, and available last reading of hemoglobin $\mathrm{A} 1 \mathrm{c}(\mathrm{HbA1c})$ were collected through personal interviews and a medical records' review using structured questionnaires and data collection forms. Good glycemic control was defined as HbA1c $\leq 7 \%$. To assess the results, the Statistical Package for Social Sciences (version 16) was used to undertake descriptive, univariate, and multivariate analyses.

Results: The mean \pm standard deviation age was $60 \pm 9.7$ years. More than half of the participants were male (51.2\%), and the majority had additional chronic diseases (88.5\%). Of the total 271 participants whose HbA1c levels have been monitored, 16.7\% had good glycemic control. Multivariate analysis showed that unemployment was significantly related to a decreased odds of good glycemic control (odds ratio=0.34; $95 \%$ confidence interval=0.12-0.98; $\mathrm{p}<0.05)$.

Conclusion: The study noted that the proportion of patients with good glycemic control was low, a result comparable to studies from many countries. Further investigation and improvement of inappropriate health-care system factors and self-care management together with educational programs that emphasize the importance of self-care management and the health-care providers' role would be of great benefit in glycemic control.

Keywords: Hemoglobin A1c, Glycemic control, Type II diabetes, Palestine.

(C) 2017 The Authors. Published by Innovare Academic Sciences Pvt Ltd. This is an open access article under the CC BY license (http://creativecommons. org/licenses/by/4. 0/) DOI: http://dx.doi.org/10.22159/ajpcr.2017.v10i9.19453

\section{INTRODUCTION}

The health-care resources limitations and availability in troubled countries such as Palestine, in addition to the need for efficient scarce resources use, have led to the diabetes prevalence which is high in Palestine and expected to increase further in future [1] as demand for clinical management, treatment, and comprehensive care rises. Diabetes is a costly disease to treat, especially in Palestine where its control and prevention resources are limited. Thus, there is a need for Palestinian authorities and organizations to track not only the disease but also the consequent economic burden placed on their society. The high diabetes incidence in Palestine is affecting the most productive age groups and is associated with significant morbidity, mortality, and economic consequences. To address this, the Palestinian ministry of health has, since 1998, developed strategies to enhance the management and treatment of diabetes in its centers and hospitals [2].

Persistent hyperglycemia is the main feature of diabetes [3]. Patients with diabetes are prone to consequences in both short-term and longterm diabetic complications. This makes diabetes health-care service more complicated and difficult to evaluate than any other diseases because the condition needs long-term assessment and evaluation to guarantee an appropriate health-care service. Thus, the main aim of management and treatment of type II diabetes is to lower fasting blood glucose to near normal levels, to prevent or at least delay the occurrence of diabetic complications. This can reduce the enormous economic costs, but in order to do so, it is very important for those in charge of diabetes primary health-care centers to ensure early diagnosis of diabetes and take into account patient education and regular follow-up through a well-organized surveillance system [4]. To achieve this, they need to adopt a conceptual model for examining health-care services such as Donabedian's framework [5].

Three categories of Donabedian's framework, namely, structure, process, and outcomes of care can draw information about health-care services. Structure describes how well a program is designed, including hospital buildings, scientific disciplines for health-care professionals, financing, and equipment. The process of care describes how well a program is implemented and the interaction between patients and health-care providers throughout the health-care delivery. Outcomes describe how well the program is evaluated and it refers to the healthcare effects [5]. These criteria are closely interrelated and must be taken into account as a single unit, together with components that are interconnected and related to each other. Diabetes control relies heavily on patient self-care management that influences almost all facets of their day-to-day activities. This study, therefore, assesses glycemic control and its relationship to patient characteristics, healthcare system factors, and self-care management among type II diabetes patients.

\section{METHODS}

\section{Study design}

This study was retrospective cross-sectional. Data collection consisted of personal interview and medical records' review for the past 1 year. Glycemic control was determined as an outcome (good versus poor glycemic control) while using sociodemographic, clinical characteristics, health-care system factors, and self-care management as independent 
variables. The study instruments have been previously used by other studies [6-16].

\section{Study setting}

Ramallah is administrative and political capital of the Palestinian government and is more developed than other Palestinian cities in economic, health, and urban terms. The study was carried out at the National Center for Chronic Diseases and Dermatology in Ramallah, the first Palestinian governmental tertiary health-care center that has a section specializing in providing diabetes care for diabetic patients with governmental health insurance in that city. During the study period, the researcher visited the center daily to recruit potential participants, interview them personally, and review their medical records.

\section{Participants}

This study was undertaken with a sample of outpatients recruited using a convenient sampling method from a medical records' list of type II diabetes patients, who visited the study setting regularly and continuously during the past 1 year. Every patient who met the inclusion criteria was asked if he/she would be willing for study participation. The information sheet was used to inform patients about the study aim, and the researcher asked them to read it carefully and sign a consent form to participate in it. Subsequently, the inclusion criteria for this study were: Patients diagnosed with type II diabetes for 1 year or more, with available medical file, currently being under medical care for type II diabetes with at least two outpatient visits during the past 1 year, and those willing for study participation. The main exclusion criteria were those suffering from Type I diabetes or gestational diabetes and those with physical and mental conditions that could interfere with their ability to understand and/or complete data collection requirements.

\section{Sample size}

There are no previous publications about glycemic control among Palestinian diabetic patients and the assumption of the maximum rate of good glycemic control in Palestine to be $50 \%$. The study required an adequate sample size from a target population of 1200 type II diabetes patients. The outcome is dichotomous (good vs. poor glycemic control), and the level of confidence was presented with a 95\% confidence interval (CI) with the significance level set at 5\% (two-tailed) [17]. Calculations estimated that a sample of 292 type II diabetes patients was needed upon using the Daniel formula. However, since the total target population is $<10,000$, an adjusted sample size of 235 patients was decided [17-19]. To minimize erroneous results and increase the study reliability, the researcher recruited a minimum sample size of 247 type II diabetes patients [20,21].

\section{Ethical approval}

This study was approved by the Palestinian Ministry of Health and Research Management Institute at Universiti Teknologi MARA. The researcher provided each participant with an information sheet copy which included a brief explanation about the study and its purposes, along with the consent form which identifies the requirements and condition of study accession, and participant's rights. The researcher also gave an individual oral explanation to participant about the study importance and their rights before asking them to sign the consent form once they agreed to join the study.

\section{Recruitment procedure}

The potential participants who met the sampling criteria were screened from the medical records. Each patient in the center's waiting area who met the sampling criteria was asked if he/she was willing to participate in the study. If the patient agreed to talk for possible participation, then a consent form was read to the patient and an approval signature obtained. Following this, the study instruments were presented and explained during the interview, and all participants completed the questionnaires and forms in a center's private area. These were later compared with their medical records. The forms and questionnaires for data collection were: Sociodemographic and health questionnaire, Patient Perception of Diabetes Care Quality Questionnaire (PPDCQ), diabetes professional performance checklist, diabetes self-care management scale, and medical records' checklist.

\section{Instruments}

Sociodemographic and health questionnaire

This questionnaire section was designed to collect data about patient characteristics. It included sociodemographic data information concerning age, gender, marital status, household monthly income, educational level, place of residence, occupation, working days and hours, and health insurance. The other part covered patient clinical characteristics data including medical history, type II diabetes duration, body mass index, smoking status, and any medications. The medical history question was presented to the participant as a list of illnesses with a dichotomous (yes/no) response [6,7]. All participants were asked to state their current antidiabetic treatment to investigate the antidiabetic therapy type as well as insulin treatment during the past 1 year. Data concerning the number of medications taken on a daily basis were collected from the medical records.

\section{Patient Perception of Diabetes Care Quality Questionnaire}

The attending physician's specialty, details of preventive education, and feedback on patient perception of patient-professional interaction together with satisfaction with this interaction were obtained and measured and using a PPDCQ [8,9]. The physician's specialty was categorized as diabetologist or non-diabetologist. If a participant could not identify the specialty, the researcher asked the physicians personally. Because there is no specific Palestinian system for diabetes care institute accreditation, criteria developed by Taiwanese Association of Diabetes Educators were used in the study after it was found best suited for assessment $[22,23]$.

The preventive education evaluation consists of five dimensions, namely, diet education, exercise education, foot care instructions, self-blood glucose monitoring, and smoking status. The score for each dimension is 10 . Therefore, the diabetes preventive education maximum total score is 50 . The cumulative preventive education percentage is the mean total score as opposed to the maximum total score. Preventive education was considered inappropriate when the mean total score was lower than the average score (the cumulative percentage is $<50 \%$ ) and appropriate if greater or equal the average score (cumulative percentage $\geq 50 \%$ ).

Patient satisfaction with professional scale is the foundation part of the PPDCQ that includes five dimensions referring to physician and four each for nurse and dietician, respectively. Two additional items asked patients if they received education and care from a nurse and/or dietician. Subsequently, the subscales of nurse and dietician were given 0 if the participant did not get any such care and education. Potential rating categories range from never (one) to always (five). Thus, scores for subscales ranged from physician (6-30), nurse (0-25), to dietician $(0-25)$. Consequently, the total patient satisfaction with professional scale score ranged from 6 to 80 . The higher the score means, the higher the patient satisfaction with health-care professionals. The mean total patient satisfaction with professional scale score was calculated as opposed to the maximum total score to calculate the cumulative percentage. Appropriate patient-professional relationship refers to a mean total patient satisfaction with professional scale score greater or equal to the average score (cumulative percentage $\geq 50 \%$ ) and inappropriate when the total score is lower than the average score (cumulative percentage $<50 \%$ ).

\section{Diabetes professional performance checklist}

The quality of follow-up is a health-care system factor represented as a measurement of diabetic complications' risk factors. Data about quality of follow-up were collected from a medical records' review and personal interviews using the diabetes professional performance checklist and the PPDCQ which included blood test evaluation for hemoglobin A1c (HbA1c), fasting blood glucose, lipid profile (cholesterol, triglycerides, high-density lipoprotein, and low-density lipoprotein), blood pressure 
checkup frequency, nephropathy assessment (serum creatinine, urine analysis, and microalbumin), feet and fungus examination, and ophthalmoscope examination [10]. The maximum score for each dimension is 10 , a total of 70 ; the maximum quality of follow-up total score. Table 1 shows the quality of follow-up measure. The cumulative percentage is the mean quality of follow-up total score as opposed to the maximum total score. The quality of follow-up was considered inappropriate when the mean total score was lower than the average score (cumulative percentage $<50 \%$ ) and appropriate when greater or equal the average score (cumulative percentage $\geq 50 \%$ ).

\section{Self-care management scale}

Diabetes self-care management were measured using a questionnaire consisting of four dimensions related to diet, physical exercise, and selfblood glucose monitoring identified the degree of following a diabetic meal plan, a frequency of 30 minutes of daily physical exercise and the number of glucose testing per week $[11,24]$, and the eight-item Morisky Medication Adherence Scale (MMAS-8) that consists of 8 items related to medication adherence [25]. The first seven items were yes/no questions while the eighth item was answered on a 5-point Likert scale. Scores can range from zero to eight, with one score given for each "No" answer except for item number five where one score was given for a "Yes" answer, and the eighth item with zero given for "all the time" and one score for "never/rarely" [6,7,12,13,26].

In the category of self-care management, follow a diabetic meal plan for 3 days or more in the previous 7 days, meant that the participants followed a diabetic meal plan as recommend by the dietician. In addition, participants who reported that they walked 3 days or more in the previous 7 days were considered as being engaged in at least 30 minutes in daily physical exercise. Self-blood glucose monitoring was defined as those who stated that they performed home glucose monitoring for 5 days or more in the previous 7 days $[27,28]$. Total medication adherence score ranged from zero to eight. Participants were classified as non-adherent if their total score was less than six and adherent for those whose total scores was six or more.

\section{Medical records' checklist}

The medical records' checklist was the basic instrument used by the researcher to collect data concerning prescribed medications, therapyrelated factors, and quality indicators of diabetes control from medical records' review $[14,16]$. A review of these using the checklist was an effective technique in examining the accuracy of participant follow-up by checking the number of recorded visits number. Therapy-related factors consist of the medication profile of type II diabetes patients. Therefore, prescribed medications for type II diabetes, antihypertensive medications, statins, and aspirin were included in the prescribed medications list studied. In addition, the antidiabetic treatment regimen was the main variable used for assessing drug treatment.

Table 2 shows the quality indicators of diabetes control. They were inclusive of $\mathrm{HbA1c}$, fasting blood glucose, cholesterol, triglycerides, highdensity lipoprotein, low-density lipoprotein, and blood pressure. The glycemic control status was categorized as good if HbA1c values were $\leq 7 \%$ and poor if $\mathrm{HbA} 1 \mathrm{c}$ values were $>7 \%$ [29]. Hypertriglyceridemia refers to a triglyceride level $\geq 150 \mathrm{mg} / \mathrm{dl}$. High-density lipoprotein is considered low when the level is $<35 \mathrm{mg} / \mathrm{dl}$ and excellent when the level is higher than $35 \mathrm{mg} / \mathrm{dl}$. Low-density lipoprotein is considered high when the level is $\geq 100 \mathrm{mg} / \mathrm{dl}$ [30]. Furthermore, patients receiving medications for any of the above conditions were considered as having the condition [27].

\section{Statistical analysis}

The Statistical Package for the Social Sciences (version 16) was used to carry out statistical analysis. Data were described as mean \pm standard deviation (SD) and median (interquartile range: Q1-Q3) for continuous variables and proportions for categorical variables. Binary logistic regression was used to assess statistical significance of the difference in the good glycemic control according to independent variables. Multiple logistic regression was carried out using variables that showed significance in binary logistic regression to identify factors related to good glycemic control. $\mathrm{p}<0.05$ was considered statistically significant.

\section{RESULT}

\section{Participants' characteristics}

A total of 330 patients were recruited. The mean \pm SD age of the participants was $60 \pm 9.7$ (range $=28-85$ ) years. More than half of the participants were male $(169,51.2 \%) .253$ participants $(76.7 \%)$ were married. The majority were low-income participants $(228 ; 69.1 \%)$ and held school certificates (220; 66.7\%). Approximately half of the participants were city residents $(168 ; 50.9 \%)$, and a higher proportion was housewives $(130 ; 39.4 \%)$. The mean \pm SD daily working hours

Table 1: Description of quality of follow-up

\begin{tabular}{|c|c|c|c|c|}
\hline Item & Frequency & Data source & Item score & Total score \\
\hline \multirow[t]{4}{*}{ HbA1c } & 1 time/year & Medical records & 2.5 & 10 \\
\hline & 2 times/year & & 5 & \\
\hline & 3 times/year & & 7.5 & \\
\hline & 4 times/year & & 10 & \\
\hline \multirow[t]{4}{*}{ Fasting blood glucose } & 1 time/year & Medical records & 2.5 & 10 \\
\hline & 2 times/year & & 5 & \\
\hline & 3 times/year & & 7.5 & \\
\hline & 4 times/year & & 10 & \\
\hline Lipid profile & 1 time/year & Medical records & & 10 \\
\hline Total cholesterol & & & 2.5 & \\
\hline Triglycerides & & & 2.5 & \\
\hline High-density lipoprotein & & & 2.5 & \\
\hline Low-density lipoprotein & & & 2.5 & \\
\hline \multirow{2}{*}{ Blood pressure measurement } & At least 2 & Medical records & 5 & 10 \\
\hline & 3-4 times/year & & 10 & \\
\hline Nephropathy assessment & 1 time/year & Medical records & & 10 \\
\hline Serum creatinine & & & 5 & \\
\hline Urine analysis & & & 5 & \\
\hline Microalbumin (with or without above) & & & 5 & \\
\hline Feet and fungus examination & Yes/No & Medical records+PPDCQ & - & 10 \\
\hline Ophthalmoscope examination & 1 time/year & Medical records+PPDCQ & 10 & 10 \\
\hline Total score & & & 70 & 70 \\
\hline
\end{tabular}

HbA1c: Hemoglobin A1c, PPDCQ: Patient Perception of Diabetes Care Quality Questionnaire 
and weekly working days were $7.4 \pm 2.5$ and $5.5 \pm 0.9$, respectively. The overwhelming majority of participants were covered by governmental health insurance only (306; 92.7\%).

Participants reported an average of $1.9 \pm 1.7$ additional diabetic complications (median=2; Q1-Q3: $0-3$ ) and $1.8 \pm 1.8$ additional non-diabetic comorbidities (median=2; Q1-Q3: 1-2), respectively. Tuberculosis $(265 ; 80.3 \%$ ) and hypertension $(208 ; 63.0 \%)$ were the most frequently reported additional chronic diseases among the participants. 38 participants (11.5\%) reported that they did not suffer from additional chronic diseases while approximately half of the participants reported four or more additional chronic diseases (166; $50.3 \%$ ). Obesity (body mass index $\geq 30 \mathrm{~kg} / \mathrm{m}^{2}$ ) was the most frequently reported (152; 46.1\%), and more than half of the participants reported that they were non-smokers (209; 63.3\%) while 207 (62.7\%) had been diagnosed with type II diabetes for more than 10 years. Participants reported an average of $6.4 \pm 2.8$ (median=6; Q1-Q3: 5-8) different medications taken on daily basis.

\section{Reported health-care system factors}

The majority of the participants reported that the physicians were diabetologists $(327 ; 99.0 \%)$. More than half of the participants reported taking a combination treatment of oral hypoglycemic drugs and insulin $(181 ; 54.8 \%) .74$ participants $(22.4 \%)$ were on insulin only and $74(22.4 \%)$ others received only oral hypoglycemic drugs. Aspirin and statins were prescribed for 188 participants (57\%) and 203 participants (61.5\%), respectively. In addition, angiotensin-converting enzyme inhibitors were taken by more than half the participants (186; $56.4 \%$ ) compared to the other prescribed therapies for hypertension taken by the other $53.6 \%$.

The mean \pm SD quality of follow-up total score was $38.8 \pm 13.2$ (median=40; Q1-Q3: 32.5-47.5), which was higher than the average score (cumulative percentage $=55.4 \%$ ). The highest quality of follow score was for blood pressure measurement (mean $\pm S D=8.8 \pm 3$ ), and $\mathrm{HbA1c}$ was found to have the lowest score (mean $\pm \mathrm{SD}=3.8 \pm 2.7$ ). The mean \pm SD preventive education total score was higher than the average score $(33.1 \pm 16.1$; cumulative percentage $=66.2 \%)$, and the median was 40 (Q1-Q3: 20-50). The mean \pm SD patient satisfaction with professional scale total score was $38.5 \pm 15.9$, which was lower than the average score (cumulative percentage $=48.1 \%$ ), and the median was 30 (Q1-Q3: 28-52). 81 participants (24.6\%) reported that they received diabetes education from nurses, and 91 (27.6\%) received diabetes education from dieticians. The mean \pm SD physician total score was 27.2 \pm 4 (median=29; Q1-Q3: 26-30). The mean \pm SD nurse and dietician total scores were $22.3 \pm 2.6$ (median=23; Q1-Q3: 20.5-24) and 21 \pm 5.1 (median=24; Q1-Q3: 20-25), respectively.

\section{Reported self-care management}

Table 2: Quality indicators of diabetes control

\begin{tabular}{ll}
\hline Item & Category \\
\hline HbA1c & $\leq 7 \%$ - good control, $>7 \%$ - poor control \\
Fasting & $90-130 \mathrm{mg} / \mathrm{dl}$ - achieved control, $>150 \mathrm{mg}$ - did not \\
blood & achieve control \\
glucose & \\
Cholesterol & $<200 \mathrm{mg} / \mathrm{dl}$ - good control, \\
& $200-220 \mathrm{mg} / \mathrm{dl}$ - acceptable, $>220 \mathrm{mg} / \mathrm{dl}$ - poor control \\
Triglycerides & $<150 \mathrm{mg} / \mathrm{dl}-$ good control, $\geq 150 \mathrm{mg} / \mathrm{dl}-$ poor control \\
High-density & $>35 \mathrm{mg} / \mathrm{dl}-$ good control, $<35 \mathrm{mg} / \mathrm{dl}-$ poor control \\
lipoprotein & \\
Low-density & $<100 \mathrm{mg} / \mathrm{dl}-$ optimal control, \\
lipoprotein & $100-130 \mathrm{mg} / \mathrm{dl}$ - acceptable control, \\
& $>130 \mathrm{mg} / \mathrm{dl}-$ poor control \\
Blood & $<140 / 90 \mathrm{mg} / \mathrm{dl}$ - good control, $>140 / 90$ - poor \\
pressure & control
\end{tabular}

More than half of the participants followed a diabetic meal plan (182; 55.2\%). 179 participants (54.2\%) participated in physical exercise, and more than one-quarter tested their blood glucose level at home (86; 26.1\%). 250 participants answered the questions regarding medication adherence. The mean \pm SD MMAS- 8 total score was $6.3 \pm 1.6$, which was higher than the average score (cumulative percentage $=78.8 \%$ ), and the median was 7 (Q1-Q3: 5.5-8). The majority were adherent (180; 72\%) while more than quarter $(70 ; 28 \%)$ were non-adherent.

\section{Description of quality indicators of diabetes control}

HbA1c was not measured for 59 participants $(17.9 \%)$. The mean \pm SD HbA1c level was 8.4 \pm 1.7 (median=8.1; Q1-Q3: 7.3-9.2). Only 20.3\% of the participants who have been pursuing their HbA1c levels achieved good glycemic control, and the glycemic control for $79.7 \%$ of them was poor, indicating a need for intensive treatment. Fasting blood glucose was not measured for 47 participants $(14.7 \%)$. The mean \pm SD fasting blood glucose level was 182 \pm 77.4 (median=165; Q1-Q3: 129-212). Based on the World Health Organization medical standards of diabetes care, less than a quarter of the participants $(23.3 \%)$ whose fasting blood glucose levels have been monitored were under acceptable control $(90-130 \mathrm{mg} / \mathrm{dl})$. The fasting blood glucose level for the rest of them $(169 ; 59.7 \%)$ was poor $(>150 \mathrm{mg} / \mathrm{dl})$.

Cholesterol level was examined for 261 participants, and only 15 (5.7\%) were within the acceptable control $(200-220 \mathrm{mg} / \mathrm{dl})$. Interestingly, none of the participants revealed a poor cholesterol level control $(>220 \mathrm{mg} / \mathrm{dl})$, and the cholesterol level control of the 246 participants $(94.3 \%)$ was good $(<200 \mathrm{mg} / \mathrm{dl})$. The triglyceride level was not measured for 95 participants (28.8\%). 93 participants $(39.6 \%)$ were within the acceptable triglyceride control $(<150 \mathrm{mg} /$ dl). However, the results were not encouraging, considering that almost $61 \%$ of those had high triglyceride level $(\geq 150 \mathrm{mg} / \mathrm{dl})$. Both high-density lipoprotein and low-density lipoprotein were examined for a very low proportion of the participants $(35,10.6 \%$; $27,8.2 \%$, respectively). The blood pressure of 16 participants (4.8\%) was not examined. Poor blood pressure control $(>140 / 90)$ was not noticed among the participants.

\section{Factors relating to good glycemic control}

The univariate analysis (Table 3) did show a significant relationship between good glycemic control and marital status, occupation, diabetes duration, and a number of medications and prescribed therapies in terms of insulin-taking and an antidiabetic treatment regimen. Married participants and those who were unemployed were less likely to have good glycemic control ([odds ratio (OR) $=0.5 ; 95 \% \mathrm{CI}$ of $0.2-0.9]$ and [OR=0.3; 95\% CI of 0.1-0.7] respectively). Participants with long diabetes duration and a high number of medications were less likely to have good glycemic control ([OR=0.95; 95\% CI of $0.91-1.00]$ and [OR=0.9; $95 \% \mathrm{CI}$ of $0.8-1.0]$ respectively). Participants who were not on insulin were more likely to be under good glycemic control ([OR=2.5; 95\% CI of 1.3-4.7]). Participants whose antidiabetic treatment regimen was a combination treatment of oral hypoglycemic drugs and insulin were less likely to be under good glycemic control ([OR=0.5; 95\% CI of 0.3-0.8]). The multivariate analysis (Table 4) showed that unemployment was significantly related to decreased odds of being under good glycemic control. Compared to those employed, unemployed participants were less likely to achieve good glycemic control ([OR $=0.34 ; 95 \% \mathrm{CI}$ of $0.12-0.98])$.

\section{DISCUSSION}

The proportion of participants with HbA1c levels $\leq 7 \%$ in this study was lower than that of the studies done in France and Spain [31,32]. In terms of comparison of the study results with that of the Al-Rowais' study of type II diabetes patients conducted in the Kingdom of Saudi Arabia [33], the percentage of participants who obtained acceptable HbA1c levels (6-8\%) was almost the same. About $66.7 \%$ of the study population in Kuwait had poor glycemic control (HbA1c $>7 \%$ ) [34]. Less than half of patients in Pakistan had HbA1c level $>7.5 \%$ (46.7\%) [35]. Glycemic control in Palestine indicates a need for more research and 
Table 3: Univariate analysis of factors related to good glycemic control

\begin{tabular}{|c|c|c|c|c|c|}
\hline Variable & $\begin{array}{l}\text { Frequency (\%) } \\
n=271\end{array}$ & $\begin{array}{l}\text { Good glycemic control } \\
n=55(20.3 \%)\end{array}$ & $\begin{array}{l}\text { Poor glycemic control } \\
n=216(79.7 \%)\end{array}$ & Odds ratio with $95 \%$ CI & p value \\
\hline \multicolumn{6}{|l|}{ Age category } \\
\hline $28-37$ & $6(2.2)$ & $3(5.5)$ & $3(1.4)$ & Reference (1) & \multirow{5}{*}{0.339} \\
\hline $38-47$ & $31(11.4)$ & $7(12.7)$ & $24(11.1)$ & $0.3(0.05-1.8)$ & \\
\hline $48-57$ & $91(33.6)$ & $14(25.5)$ & 77 (35.6) & $0.2(0.0-1.0)$ & \\
\hline $58-67$ & $96(35.4)$ & $20(36.4)$ & $76(35.2)$ & $0.3(0.1-1.4)$ & \\
\hline$\geq 68$ & 47 (17.3) & $11(20.0)$ & $36(16.7)$ & $0.3(0.1-1.7)$ & \\
\hline Male & $138(50.9)$ & $23(41.8)$ & $115(53.2)$ & Reference (1) & \multirow[t]{2}{*}{0.132} \\
\hline Female & $133(49.1)$ & $32(58.2)$ & $101(46.8)$ & $1.6(0.9-2.9)$ & \\
\hline \multicolumn{6}{|l|}{ Marital status } \\
\hline Single & $65(24.0)$ & $20(36.4)$ & $45(20.8)$ & Reference (1) & \multirow[t]{2}{*}{0.018} \\
\hline Married & $206(76.0)$ & $35(63.6)$ & $171(79.2)$ & $0.5(0.2-0.9)$ & \\
\hline \multicolumn{6}{|l|}{ Income level (JDs) } \\
\hline$<500$ & $187(69.0)$ & $32(58.2)$ & 155 (71.8) & Reference (1) & \multirow[t]{2}{*}{0.054} \\
\hline$\geq 500$ & $84(31.0)$ & $23(41.8)$ & $61(28.2)$ & $1.8(1.0-3.4)$ & \\
\hline Illiterate & $28(10.3)$ & $7(12.7)$ & $21(9.7)$ & Reference (1) & \multirow[t]{3}{*}{0.183} \\
\hline$\leq$ High school & $181(66.8)$ & $31(56.4)$ & $150(69.4)$ & $0.6(0.2-1.6)$ & \\
\hline$>$ High school & $62(22.9)$ & $17(30.9)$ & $45(20.8)$ & $1.1(0.4-3.1)$ & \\
\hline \multicolumn{6}{|l|}{ Occupation } \\
\hline Employed & $103(38.0)$ & $26(47.3)$ & $77(35.6)$ & Reference (1) & \multirow[t]{3}{*}{0.036} \\
\hline Unemployed & $61(22.5)$ & $5(9.1)$ & $56(25.9)$ & $0.3(0.1-0.7)$ & \\
\hline Housewife & $107(39.5)$ & $24(43.6)$ & $83(38.4)$ & $0.9(0.5-1.6)$ & \\
\hline \multicolumn{6}{|l|}{ Place of residence } \\
\hline City & $140(51.7)$ & $32(58.2)$ & $108(50.0)$ & Reference (1) & \multirow[t]{2}{*}{0.279} \\
\hline Village and refugee camp & $131(48.3)$ & $23(41.8)$ & $108(50.0)$ & $0.7(0.4-1.3)$ & \\
\hline Number of chronic diseases & $4.0(2.0-6.0)$ & $3.0(1.0-5.0)$ & $4.0(2.0-6.0)$ & $0.9(0.8-1.0)$ & 0.116 \\
\hline \multicolumn{6}{|l|}{ Body mass index } \\
\hline Normal & $45(16.6)$ & $12(21.8)$ & $33(15.3)$ & Reference (1) & \multirow[t]{3}{*}{0.500} \\
\hline Overweight & $98(36.2)$ & $18(32.7)$ & $80(37.0)$ & $0.6(0.3-1.4)$ & \\
\hline Obese & $128(47.2)$ & $25(45.5)$ & $103(47.7)$ & $0.7(0.3-1.5)$ & \\
\hline Diabetes duration & $14.0(9.0-20.0)$ & $12.0(6.0-16.0)$ & $15.0(10.0-20.0)$ & $0.95(0.91-1.00)$ & 0.035 \\
\hline \multicolumn{6}{|l|}{ Smoking status } \\
\hline Insulin treatment & & & & & \\
\hline Yes & $207(76.4)$ & $34(61.8)$ & $173(80.1)$ & Reference (1) & 0.005 \\
\hline No & $64(23.6)$ & $21(38.2)$ & $43(19.9)$ & $2.5(1.3-4.7)$ & \\
\hline Antidiabetic therapy & & & & & \\
\hline Monotherapy & $112(41.3)$ & $31(56.4)$ & $81(37.5)$ & Reference (1) & 0.012 \\
\hline Combination & $159(58.7)$ & $24(43.6)$ & $135(62.5)$ & $0.5(0.3-0.8)$ & \\
\hline Followed a diabetic meal plan & & & & & \\
\hline Yes & $157(57.9)$ & $32(58.2)$ & $125(57.9)$ & $1.0(0.6-1.8)$ & 0.967 \\
\hline No & $114(42.1)$ & $23(41.8)$ & $91(42.1)$ & Reference (1) & \\
\hline Physical exercise participation & & & & & \\
\hline Yes & $140(51.7)$ & $31(56.4)$ & $109(50.5)$ & $1.3(0.7-2.3)$ & 0.435 \\
\hline No & $131(48.3)$ & $24(43.6)$ & $107(49.5)$ & Reference (1) & \\
\hline Self-blood glucose monitoring & & & & & \\
\hline Yes & $69(25.5)$ & $16(29.1)$ & $53(24.5)$ & $1.3(0.7-2.4)$ & 0.489 \\
\hline No & $202(74.5)$ & $39(70.9)$ & $163(75.5)$ & Reference (1) & \\
\hline Medication adherence & & & & & \\
\hline Adherent & $147(73.1)$ & $35(77.8)$ & $112(71.8)$ & $1.4(0.6-3.0)$ & 0.426 \\
\hline Non-adherent & $54(26.9)$ & $10(22.2)$ & $44(28.2)$ & Reference (1) & \\
\hline Quality of follow-up score & $42.5(35.0-50.0)$ & $42.5(35.0-45.0)$ & $42.5(35.0-50.0)$ & $0.98(0.96-1.01)$ & 0.188 \\
\hline Preventive education score & $40.0(30.0-50.0)$ & $40.0(20.0-40.0)$ & $40.0(30.0-50.0)$ & $0.99(0.97-1.01)$ & 0.217 \\
\hline PSPS score & $30.0(28.0-52.0)$ & $30.0(28.0-52.0)$ & $30.0(28.0-52.8)$ & $1.01(0.99-1.03)$ & 0.341 \\
\hline
\end{tabular}

n: Valid number, CI: Confidence interval, JDs: Jordanian dinars, PSPS: Patient satisfaction with professional scale

improvement. The fasting blood glucose level for more than half of the participants indicates a need for intensive treatment and a diet regimen. This sheds light to review diabetes care infrastructure and policies to develop awareness of issues concerning diabetes health-care service.

Blood lipid examination was done with each component separately. Hypercholesterolemia and hypertriglyceridemia were major treatable cardiovascular disease risk factors among the participants [36]. Hence, the results proved that steps must be taken to improve their lipid profile control. This is another medical health outcome and part of the diabetes health-care system. The blood pressure can be addressed if both patients and health-care professionals can be made aware of the seriousness of hypertension and the need to provide a test for this as part of diabetes care [37]. In addition, the availability of standard clinical guidelines for blood pressure management, training programs for healthcare professionals which result in the ease of using blood pressure screening device, as well as easy and efficient access to blood pressure management services is desirable [38]. Blood pressure 
Table 4: Multivariate analysis of factors related to good glycemic control

\begin{tabular}{|c|c|c|c|c|c|}
\hline Variable & Coefficient $(\beta)$ & SE & Wald & Odds ratio with $95 \%$ CI & p value \\
\hline \multicolumn{6}{|l|}{ Marital status } \\
\hline Single & & & & Reference (1) & 0.065 \\
\hline Married & -0.69 & 0.37 & 3.41 & $0.50(0.24-1.04)$ & \\
\hline \multicolumn{6}{|l|}{ Occupation } \\
\hline Employed & & & & Reference (1) & \\
\hline Unemployed & -1.08 & 0.54 & 4.03 & $0.34(0.12-0.98)$ & 0.045 \\
\hline Housewife & -0.28 & 0.38 & 0.56 & $0.76(0.36-1.58)$ & 0.455 \\
\hline Number of medications & -0.11 & 0.06 & 3.28 & $0.89(0.79-1.01)$ & 0.070 \\
\hline \multicolumn{6}{|l|}{ Insulin treatment } \\
\hline Yes & & & & Reference (1) & 0.726 \\
\hline No & 0.18 & 0.51 & 0.12 & $1.20(0.44-3.27)$ & \\
\hline \multicolumn{6}{|l|}{ Antidiabetic therapy } \\
\hline Monotherapy & & & & Reference (1) & 0.379 \\
\hline Combination & -0.38 & 0.44 & 0.77 & $0.68(0.29-1.60)$ & \\
\hline
\end{tabular}

SE: Standard error, CI: Confidence interval

examination is the first measurement that should be done.

The finding of the univariate analysis of factors relating to good glycemic control is inconsistent with what is reported by other studies [39,40], but consistent with others $[39,41]$ which noted that a progressive impairment of insulin secretion results from pancreatic $\beta$-cell failure, worsening type II diabetes over time, may lead to a negative impact on patient response to diet alone and/or oral hypoglycemic drugs and the need for a combination treatment of oral hypoglycemic drugs and insulin, higher doses, and/or additional medication which increases over time. However, an interrupted insulin supply in some cases and high insulin prices outside the governmental centers and the discomfort of insulin usage compared to oral hypoglycemic drugs could be a causal factor in poor glycemic control due to the insulin supply delay for more progressive type II diabetes patients.

The result of multivariate analysis as with previous studies is attributed to lower income and lack of family support, depression and poor mental health due to the living difficulties, and the lack of minimum basic needs. These or a combination of them have resulted in patient reluctance to visit the clinic regularly, possibly due in part to feeling uncomfortable when asked questions [42-46]. The lack of a significant relationship between self-care management and glycemic control in the study is inconsistent with almost all of the previous studies [27,47-49]. This finding reflects a limited participant's credibility in answering self-care management items. Continuous education is recommended for motivating patients to overcome this and encourage them to tell the truth. This study was the first conducted in Palestine to examine the diabetes health-care services through identifying possible significant predictors for good glycemic control using binary and multiple logistic regression procedures. However, this study is cross-sectional and cannot establish causal and sequential relationships. This study may also be limited by sample and recall bias because its findings concerning self-care management were not congruent with the multiple studies' findings.

\section{CONCLUSION}

The quality of follow-up and preventive education was appropriate, but apparently, patient-professional relationship was inappropriate. These findings need further investigation because of the marked disparity of times, at which HbA1c levels were tested among the participants. However, the study is a preliminary indication that diabetes healthcare service in Palestine has a great deal of room for research and improvement. A clear health policy is needed in the diabetes management, and it is vital for health-care professionals to focus on unemployed patients with a long diabetes duration, inappropriate health-care system factors, and prescription patterns compatible with a non-interrupted insulin supply which constitutes the most prominent challenge to health-care providers and patients alike. An important initiative that needs to be adopted is the provision of a base for continuous prescription audit in the primary care setting.

The lack of a significant relationship between health-care system factors, self-care management, and good glycemic control is significant indicators of the need for an educational program that emphasizes lifestyle modification and the self-care management importance. The health-care provider's role is also an essential factor in glycemic control. Longitudinal research with multivariate causal models is recommended, as are other factors such as diabetes-related knowledge, belief in medication, and social support, for further investigation.

\section{ACKNOWLEDGMENT}

We would like to take this opportunity to express our thanks and gratitude to the faculty of pharmacy, and Institute of Research Management and Innovation (Academic and Research Assimilation Project Code 600-IRMI/DANA 5/3/ARAS (0116/2016)), UiTM, and the Palestinian Ministry of Health for all of the facilities and support have been given throughout the period of data collection in the National Center for Chronic Diseases and Dermatology.

\section{REFERENCES}

1. World Health Assembly. Health Conditions in the Occupied Palestinian Territory, Including East Jerusalem, and in the Occupied Syrian Golan-10 November; 2013. Available from: http://www.apps.who.int/ iris/handle/10665/80047

2. World Health Organization. Use of Glycated Haemoglobin (Hbalc) in the Diagnosis of Diabetes Mellitus: Abbreviated Report of a Who Consultation - 13 August; 2014. Available from: http://www.who.int/ diabetes/publications/diagnosis_diabetes2011/en.

3. Vijan S, Hayward RA. Treatment of hypertension in Type 2 diabetes mellitus: Blood pressure goals, choice of agents, and setting priorities in diabetes care. Ann Intern Med 2003;138(7):593-602.

4. World Health Organization. Management of Diabetes Mellitus Standards of Care and Clinical Practice Guidelines - 13 June; 2012. Available from: http://www.apps.who.int/iris/bitstream/10665/116245/1/dsa509.pdf.

5. Krentz AJ, Bailey CJ. Oral antidiabetic agents: Current role in type 2 diabetes mellitus. Drugs 2005;65(3):385-411.

6. Ashur ST, Shah SA, Bosseri S, Fah TS, Shamsuddin K. Glycaemic control status among Type 2 diabetic patients and the role of their diabetes coping behaviours: A clinic-based study in Tripoli, Libya. Libyan J Med 2016;11(1):31086.

7. Zyoud SH, Al-Jabi SW, Sweileh WM, Morisky DE. Relationship of treatment satisfaction to medication adherence: Findings from a crosssectional survey among hypertensive patients in Palestine. Health Qual Life Outcomes 2013;11:191.

8. de Bruin SR, van Oostrom SH, Drewes HW, de Jong-van Til JT, Baan CA, Struijs JN. Quality of diabetes care in Dutch care groups: No differences between diabetes patients with and without co-morbidity. 
Int J Integr Care 2013;13:e057.

9. Nau DP, Pacholski AM. Impact of pharmacy care services on patients' perceptions of health care quality for diabetes. J Am Pharm Assoc 2007;47(3):358-65.

10. NCQA/ADA Diabetes. Ncqa/Ada Diabetes Physician Recognition Program - 30 August; 2012. Available from: http://www.ncqa.org/ programs/recognition/clinicians/diabetes-recognition-program-drp.

11. Albikawi ZF, Abuadas M. Diabetes self-care management behaviours among Jordanian type two diabetes patients. Am Int J Contemp Res 2015;5(3):87-95

12. Sweileh WM, Zyoud SH, Abu Nab'a RJ, Deleq MI, Enaia MI, Nassar $\mathrm{SM}$, et al. Influence of patients' disease knowledge and beliefs about medicines on medication adherence: Findings from a cross-sectional survey among patients with type 2 diabetes mellitus in Palestine. BMC Public Health 2014;14:94.

13. Jamous RM, Sweileh WM, Abu-Taha AS, Sawalha AF, Zyoud SH, Morisky DE. Adherence and satisfaction with oral hypoglycemic medications: A pilot study in Palestine. Int $J$ Clin Pharm 2011;33(6):942-8.

14. Aday LA. Evaluating the Healthcare System: Effectiveness, Efficiency, and Equity. Chicago: Health Administration Press; 2004.

15. Akel M, Hamadeh G. Quality of diabetes care in a university health center in Lebanon. Int J Qual Health Care 1999;11(6):517-21.

16. Aiken LH, Sochalski J, Lake ET. Studying outcomes of organizational change in health services. Med Care 1997;35 11 Suppl: NS6-18.

17. Naing L, Winn T, Rusli BN. Practical issues in calculating the sample size for prevalence studies. Arch Orofac Sci 2006;1:9-14.

18. Daniel WW. Biostatistics: A Foundation for Analysis in the Health Sciences. 7th ed. New York: John Wiley \& Sons; 1999.

19. Singh AS, Masuku MB. Sampling techniques and determination of sample size in applied statistics research: An overview. Int J Econ Commer Manag 2014;2:1-22.

20. Daniel WW. Biostatistics: Basic concepts and methodology for the health sciences. New Jersey: John Wiley \& Sons; 2010.

21. Palestinian Ministry of Health. Annual Health Report Palestine - 20 February; 2013. Available from: http://www.moh. ps/Content/Books/nbcgI6bZxmosmDSuKLtbaawjztq8IwQ5N9 1 Y $138 \mathrm{fwj}$ S62fZBq9m4Qi_CcymmeY 82 fpborVA7zMqOQ h4bFPeaMB4po PS5svvyLVEIRyeXzfBE8.pdf.

22. Bureau of Health Promotion DoH. Overview of Health Promotion in Taiwan - 4 June; 2013. Available from: http://www.pitt. edu/ super7/49011-50001/49111-49121.pdf.

23. DOH Taiwan. Community Volunteer and Diabetes Health Education Trial - 11 April; 2012. Available from: http://www.bhp.doh.gov.tw/ snew/doc.

24. Toobert DJ, Glasgow RE. Assessing diabetes self-management: The summary of diabetes self-care activities questionnaire. Handbook of Psychology and Diabetes. Switzerland: Harwood Academic; 1994. p. 351-75.

25. Morisky DE, Ang A, Krousel-Wood M, Ward HJ. Predictive validity of a medication adherence measure in an outpatient setting. J Clin Hypertens (Greenwich) 2008;10(5):348-54

26. Sweileh WM, Ihbesheh MS, Jarar IS, Sawalha AF, Abu Taha AS, Zyoud $\mathrm{SH}$, et al. Differences in medication adherence, satisfaction and clinical symptoms in schizophrenic outpatients taking different antipsychotic regimens. Curr Drug Saf 2011;6(5):285-90.

27. Khattab M, Khader YS, Al-Khawaldeh A, Ajlouni K. Factors associated with poor glycemic control among patients with type 2 diabetes. J Diabetes Complications 2010;24(2):84-9.

28. Shrivastava SR, Shrivastava PS, Ramasamy J. Role of self-care in management of diabetes mellitus. J Diabetes Metab Disord 2013;12(1):14

29. World Health Organization. Technical Discussion on Medicine Prices and Access to Medicines in the Eastern Mediterranean Region - 5 November; 2014. Available from: http://www.applications.
emro.who.int/docs/EM RC54 Tech Disc 1 en.pdf?ua=1.

30. Haffner SM;American Diabetes Association. Dyslipidemia management in adults with diabetes. Diabetes Care 2004;27 Suppl 1:S68-71

31. Alonso-Fernández M, Mancera-Romero J, Mediavilla-Bravo JJ, Comas-Samper JM, López-Simarro F, Pérez-Unanua MP, et al. Glycemic control and use of A1c in primary care patients with type 2 diabetes mellitus. Prim Care Diabetes 2015;9(5):385-91.

32. Miller PE, Perez V. Low-calorie sweeteners and body weight and composition: A meta-analysis of randomized controlled trials and prospective cohort studies. Am J Clin Nutr 2014;100(3):765-77.

33. Al-Rowais NA. Glycemic control in diabetic patients in King Khalid University Hospital (KKUH)-Riyadh-Saudi Arabia. Saudi Pharm J 2014;22(3):203-6

34. Al-Sultan FA, Al-Zanki N. Clinical epidemiology of Type 2 diabetes mellitus in Kuwait. Kuwait Med J 2005;37(2):98-104

35. Habib SS, Aslam M. Risk factors, knowledge and health status in diabetic patients. Saudi Med J 2003;24(11):1219-24.

36. Arafat M, Salam A, Arafat O. The association of Type 2 diabetes with obesity and other factors: In multinational community. Int J Pharm Pharm Sci 2014;6(9):257-60.

37. Soubra L, Nureddin H, Omar AG, Saleh M. Factors associated with hypertension prevalence and control among lebanese Type 2 diabetic patients. Int J Pharm Pharm Sci 2016;8(10):153-9.

38. Delavari A, Alikhani S, Nili S, Birjandi RH, Birjandi F. Quality of care of diabetes mellitus type II patients in Iran. Arch Iran Med 2009;12(5):492-5

39. Valle T, Koivisto VA, Reunanen A, Kangas T, Rissanen A. Glycemic control in patients with diabetes in Finland. Diabetes Care 1999;22(4):575-9.

40. Verma M, Paneri S, Badi P, Raman PG. Effect of increasing duration of diabetes mellitus type 2 on glycated hemoglobin and insulin sensitivity. Indian J Clin Biochem 2006;21(1):142-6.

41. Spoelstra JA, Stolk RP, Cohen D, Klungel OH, Erkens JA, Leufkens HG, et al. Antipsychotic drugs may worsen metabolic control in type 2 diabetes mellitus. J Clin Psychiatry 2004;65(5):674-8.

42. Anderson RJ, Freedland KE, Clouse RE, Lustman PJ. The prevalence of comorbid depression in adults with diabetes: A meta-analysis. Diabetes Care 2001;24:1069-78.

43. Chlebowy DO, Garvin BJ. Social support, self-efficacy, and outcome expectations: Impact on self-care behaviors and glycemic control in Caucasian and African American adults with type 2 diabetes. Diabetes Educ 2006;32(5):777-86.

44. Kaholokula JK, Haynes SN, Grandinetti A, Chang HK. Biological, psychosocial, and sociodemographic variables associated with depressive symptoms in persons with type 2 diabetes. J Behav Med 2003;26(5):435-58.

45. Rubin RR. Adherence to pharmacologic therapy in patients with type 2 diabetes mellitus. Am J Med 2005;118 Suppl 5A:27S-34.

46. Vijan S, Stuart NS, Fitzgerald JT, Ronis DL, Hayward RA, Slater S, et al. Barriers to following dietary recommendations in type 2 diabetes. Diabet Med 2005;22(1):32-8

47. El-Kebbi IM, Cook CB, Ziemer DC, Miller CD, Gallina DL, Phillips LS. Association of younger age with poor glycemic control and obesity in Urban African Americans with type 2 diabetes. Arch Intern Med 2003;163(1):69-75.

48. Nichols GA, Hillier TA, Javor K, Brown JB. Predictors of glycemic control in insulin-using adults with type 2 diabetes. Diabetes Care 2000;23(3):273-7.

49. Rothenbacher D, Rüter G, Saam S, Brenner H. Younger patients with type 2 diabetes need better glycaemic control: Results of a communitybased study describing factors associated with a high $\mathrm{HbAlc}$ value. $\mathrm{Br}$ J Gen Pract 2003;53(490):389-91. 